\title{
Spatio-temporal trends and distribution patterns of typhoid disease in Uganda from 2012 to 2017
}

\author{
Kamukama Ismail, ${ }^{1,2}$ Gilbert Maiga, ${ }^{1}$ Denis Ssebuggwaawo, ${ }^{2}$ Peter Nabende, ${ }^{1}$ Ali Mansourian ${ }^{3}$ \\ ${ }^{1}$ Department of Information Systems, Makerere University, Kampala, Uganda; ${ }^{2}$ Department of Computer \\ Science, Kyambogo University, Kyambogo, Uganda; ${ }^{3}$ Department of Physical Geography, Lund University, \\ Lund, Sweden
}

\begin{abstract}
Typhoid disease continues to be a global public health burden. Uganda is one of the African countries characterized by high incidences of typhoid disease. Over $80 \%$ of the Ugandan districts are endemic for typhoid, largely attributable to lack of reliable knowledge to support disease surveillance. Spatial-temporal studies exploring major characteristics of the disease within the local population have remained limited in Uganda. The main goal of the study was to reveal spatial-temporal trends and distribution patterns of typhoid disease in Uganda for the period 2012 to 2017. Spatial-temporal statistics revealed monthly and annual trends of the disease at both regional and national levels. Results show that outbreaks occurred during 2015 and 2017 in central and eastern regions, respectively. Spatial scan statistic using the discrete Poisson model revealed spatial clusters of the disease for each of the years from 2012 to 2017 , together with populations at risk. Most of the disease clustering was in the central region, followed by western and eastern regions $(\mathrm{P}<0.01)$. The northern region was the safest throughout the study period. This knowledge helps surveillance teams to i) plan and enforce preventive measures; ii)
\end{abstract}

Correspondence: Kamukama Ismail, Makerere University, P.O. Box 7062 Kampala, Uganda.

Tel.: +256.772.374841, +256.703 .374841 .

E-mail: Kamukama@cis.mak.ac.ug

Key words: Spatial; temporal; trends; patterns; typhoid; Uganda.

Acknowledgements: The research is being sponsored by MakerereSIDA Phase (iv) Programme and supported by Kyambogo University. Uganda Ministry of Health provided clinical data and Uganda Bureau of Statistics provided population data and Uganda shape files.

Conflict of interests: The authors declare no potential conflict of interests.

Received for publication: 29 January 2020.

Accepted for publication: 18 August 2020.

(C) Copyright: the Author(s), 2020

Licensee PAGEPress, Italy

Geospatial Health 2020; 15:860

doi:10.4081/gh.2020.860

This article is distributed under the terms of the Creative Commons Attribution Noncommercial License (CC BY-NC 4.0) which permits any noncommercial use, distribution, and reproduction in any medium, provided the original author(s) and source are credited. effectively prepare for outbreaks; iii) make targeted interventions for resource optimization; and iv) evaluate effectiveness of the intervention methods in the study period. This exploratory research forms a foundation of using Geographical Information Systems (GIS) in other related subsequent research studies to discover hidden spatial patterns that are difficult to discover with conventional methods.

\section{Introduction}

Typhoid disease remains a worldwide public health burden with a high mortality and with varying epidemiological characteristics across the globe (Marks et al., 2017). It is estimated that 17.8 million cases of typhoid fever occur each year in low- and middleincome countries (Antillón et al., 2017). The highest incidence numbers are seen in Africa and central, southern and south-eastern parts of Asia (Lee et al., 2016; WHO, 2017). In Uganda, over 80\% of the districts are endemic for typhoid with those in the central and western regions topping the list (Agwu, 2012; Walters, et al., 2014), making Uganda only second to Nigeria in Africa with respect to typhoid (Jong-Hoon, 2017). New cases continue to be registered every day in many hospitals and clinics, and outbreaks are reported in different parts of the country (Kabwama et al., 2015; Mirembe et al., 2019). The disease is caused by a Gramnegative bacterium called Salmonella enterica serovar typhi, whose main route into the body is with drinking unsafe water or eating contaminated food as a result of poor sanitation and hygiene (Tiwari and Nayak, 2017; Mirembe et al., 2019).

Many research studies associate disease with location and time due to certain environments and weather conditions, such as rainfall, high temperatures, flooding and humidity being conducive for the survival and growth of disease-causing organisms (Lee et al., 2016; Gu et al., 2017). Conditions change from season to season with direct influence on health and the issue of location influencing health is not new. Already, Hippocrates (around 400 B.C.E) in his book Airs, waters and places discovered that location can influence health and this is supported by many later research studies holding that diseases tend to occur in some places and not in others (Rajabi, 2015; Adams, 2017; Malone et al., 2019). Dr John Snow famously used this concept to discover the source of cholera after an outbreak in London in 1854 (Smith, 2002). This was the first work on what is now called spatial epidemiology, which is the description and analysis of geographic variations in diseases with respect to demographic, environmental, behavioural, socio-economic, genetic and infectious risk factors (Elliott and Wartenberg 2004; Bergquist and Rinaldi, 2010; Agboola and Mataimaki, 2017). As the nature of disease charac- 
teristics are spatial and temporal in nature, they require spatio-temporal statistics to be explored. Such statistics has been used to analyze events in the two-dimensional trait of place and time (Baaghideh et al., 2016). Knowledge that can be revealed by spatio-temporal studies include incidence rates, trends, disease distributions as well as attributes, such susceptible population groups including low and high-risk areas. This knowledge is essential in disease surveillance (Ahangarcani et al, 2019), as it enables the study of populations at risk through the use of surveillance teams that can i) plan and enforce preventive measures; ii) effectively prepare for outbreaks; iii) make targeted interventions for resource optimization; iv) explore possible factors influencing disease occurrence; and v) evaluate effectiveness of intervention methods (Mirembe et al., 2019).

The current disease surveillance in World Health Organization (WHO) member states is based on an Integrated Disease Surveillance and Response (IDSR) framework and includes implementation of International Health Regulations (IHR). IDSR was developed and adopted in 1998 for Africa as a complete health approach to detect, confirm, and respond to high-priority diseases (WHO, 2015). According to IDSR and IHR, data are collected from treatment centres (health centres and hospitals) and then submitted to district level databases. The district authorities then submit the data to national databases on a weekly basis. If the data reflect that a disease is posing a serious health threat, it is remitted to WHO regional office database for WHO recommendations (Kasoro et al., 2013). Much patient data has been accumulated under this framework but without a strict spatial component (geographical coordinates) attached, which makes in-depth data analysis difficult. The data collected cannot be fully utilized as they often leave out spatio-temporal characteristics of the diseases, which eventually makes surveillance costly and inefficient (Muhindo et al., 2016).

Geographical Information Systems (GIS) and spatial statistics can reveal important epidemiological characteristics, e.g., by introducing centroids of spatial units. The main objective of our research was to use GIS to explore epidemiological characteristics of typhoid disease in the Ugandan population using district centroids together with archived data for the period 2012 to 2017. This knowledge is as essential in disease surveillance as it is for effective planning, decision-making and resource optimization. The research forms a foundation for the future use of GIS in research to explore hidden spatial patterns in the data that are difficult to discover with conventional methods.

\section{Materials and methods}

\section{Study area}

Uganda is an African country with a current population of approximately 44.27 million people and $241,038 \mathrm{~km}^{2}$ of land (WPR, 2020). As of 2012, the administrative units in Uganda consist of 112 districts composing four larger territories, i.e. the central, eastern, northern and western regions (UBOS, 2012). The central region is composed of 24 districts, the eastern of 32 districts, the northern of 30 districts and the western of 26 districts (Figure 1). The central region is highly urbanized with high population densities involving multi-ethnicities with different social and cultural behaviours (UBOS, 2016).
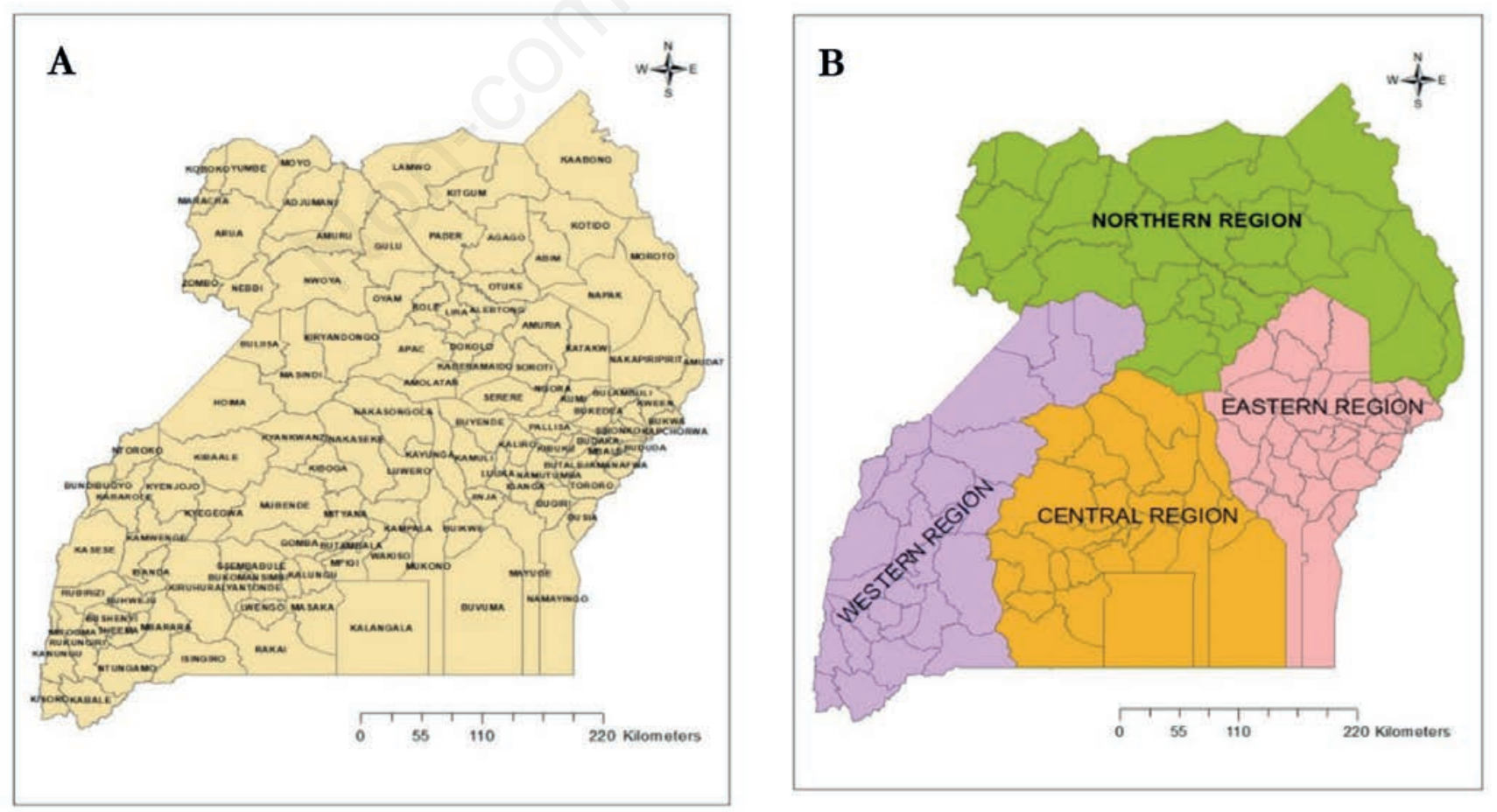

Figure 1. Map of Uganda and showing regions and districts. A) The 112 districts of Uganda; B) The four regions of Uganda. 


\section{Data sources}

A total of 1,263,923 clinically confirmed typhoid disease cases from all 112 districts organized by month and covering the period 2012 to 2017 were obtained from Uganda Ministry of Health $(\mathrm{MOH})$. To avoid breach of patients' data confidentiality law, the data were first aggregated and then organized per district. Average rainfall data from 2012 to 2017 was obtained from Uganda National Metrological Authority (UNMA). The weather data are collected by 18 weather stations that are well distributed nationally to represent all parts of the country. Ugandan shape files and population data were obtained from Uganda Bureau Of Statistics (UBOS). According to UNMA, Uganda has a bi-model climate type, which means a rainy season from March to May and another from November to December with dry seasons from January to February and from June to September. The central Region always receives the highest amount of rainfall, which results into excessive floods with poor drainage (Thieme and Jacobs, 2012). This fact is confirmed by the amounts of rainfall in the country as seen in Figure 2. After the heavy rains, some districts in the central region, including Nakeseke, Nakasongola and neighbouring areas, experience long droughts every year, which cause serious water scarcity.

\section{Materials and methods}

Mapping and analysis were done using ArcGIS software, version 10.1, (ESRI, Redlands, CA, USA) and SatScan free software package (SaTScan, 2019). Additional analysis and graphing of disease trends were done using Microsoft Excel, Office 2016. The disease cases were aggregated per district, per month and per year from 2012 to 2017. They were then aggregated per region for the entire study period.

The data were analyzed with respect to each of the four regions and for each of the years from 2012 to 2017. They were further analyzed at national level. The total number of typhoid cases in each region was computed for each of the six years. The monthly totals per region were expressed as percentages of the respective annual totals. The monthly totals for the entire six-year period were expressed as percentages of the overall total number of cases. The correlation of typhoid incidence with average rainfall was determined using Pearson's correlation coefficient (r). Incidence maps were used to explore spatio-temporal disease distribution using districts as the spatial unit for each of the years from 2012 to 2017. Spatio-temporal clusters were determined at the $95 \%$ level of confidence using the spatial scan statistic method as presented by Prates et al. (2014). A cluster was defined as when at least two neighbouring spatial units both have high Relative Risks (RRs) of the disease. Due to low and discrete disease numbers of incidence, the discrete Poisson model was accorded for spatial clustering analysis. According to Prates et al. (2014), the model uses a circle of varying radius and a predefined upper limit. To detect clusters this circle is moved across the map of the study area while varying its radius. If the study map is named $A$ and the circle of interest $Z$, the likelihood of a cluster in $Z$ is $\left(L_{Z}\right)$ according this model is determined by the following equation:

$$
L_{Z}=\left[\frac{N_{Z}}{E_{Z}}\right]^{N_{Z}}\left[\frac{N-N_{Z}}{N-E_{Z}}\right]^{N-N_{Z}} I\left(N_{Z}>E_{Z}\right)
$$

where $N$ is the total number of disease cases in the study area in question, with $\boldsymbol{N}_{Z}$ and $\boldsymbol{E}_{Z}$ the observed and expected number of disease cases in circle $\boldsymbol{Z}$.

The circle with the maximum likelihood ratio $\left(\frac{L_{Z}}{L_{0}}\right)$ forms a candidate cluster, where $\boldsymbol{L}_{\boldsymbol{0}}$ is the likelihood of a cluster under the null hypothesis (nonexistence of a cluster).

If the RR in circle $\mathrm{Z}$ can be expressed $\lambda_{z}$ as by equation 2 :

$$
\lambda_{Z}=\frac{E\left(Y_{Z}\right)}{E_{Z}}
$$

where $E\left(Y_{z}\right)$ is the expected value of the Poisson random variable of counts within circle $Z$ and $\frac{P_{Z}}{P_{\text {Total }}} N$ where $P_{z}$ is the population within circle $\mathrm{Z}$ and $P_{\text {Total }}$ the total population at risk in map A.
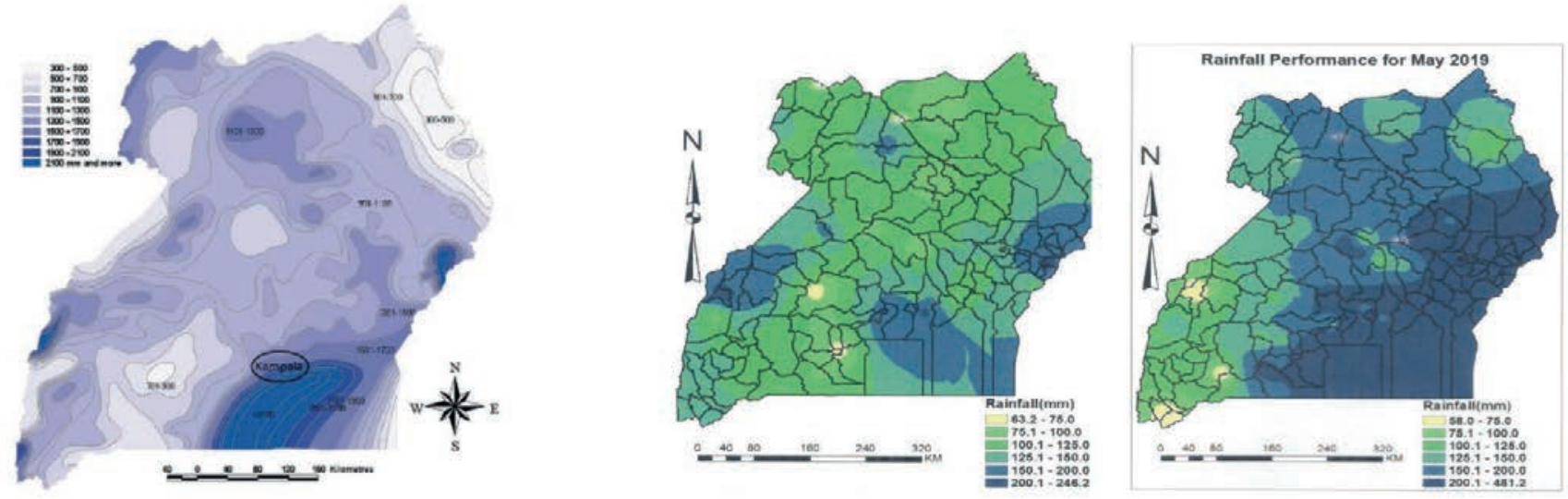

Figure 2. The average rainfall over Uganda to the rainfall for April and May 2019 (NEMA, 2009; UNMA, 2019 ). 
If $\lambda_{z}=1$, then the RR is as expected, i.e. neither a very high number of cases nor a very low one compared to historical, known values. If $\lambda_{z}<1$, there is relatively low risk in $Z$ and if $\lambda_{z}>1$, there is relatively high risk in $Z$.

As the model can be severely affected by excess zeros in the data and give misleading results (Weaver et al., 2015), the data were aggregated from monthly to annual level analysis in order to achieve at least a non-zero value for every district.

\section{Results}

\section{Spatio-temporal trends of typhoid disease}

The overall trend of typhoid in Uganda during the study period had a high peak in April-June 2015 (Figure 3). Taking also the spatial component into account, we present the spatio-temporal trends of typhoid disease using three approaches, the first of which presents monthly disease trends at the regional level for each of the study years. The second approach presents monthly disease trends at the national level for the entire period from 2012 through 2017, while the third approach presents trends and the correlation of typhoid incidences with average rainfall during both rainy and dry seasons for the entire study period.

\section{Monthly trends of typhoid disease at the regional level}

The monthly trends of typhoid disease at the regional level for each of the study years is summarized and presented using graphs (Figure 4). From this figure, it is evident that the central region had the highest percentage of typhoid incidences throughout the study period. The northern region had the least number of incidence during the same period. Figures $4 \mathrm{D}$ and $4 \mathrm{~F}$ show that the central and eastern regions experienced disease outbreaks in 2015 and 2017, respectively. In almost all of the study years, and all regions, the disease incidence began to increase from March to May, peaking between June and July to become lower in the period from August to September. Disease incidence again increased from September showing relatively lower peaks in October and November to finally fall back in December. The annual proportions of typhoid disease at the regional level from 2012 to 2017 are presented in Figure 5 , which further confirms that the central region had the highest proportion of disease incidence followed by the western and eastern regions for all years investigated. The northern region had the least disease throughout the study period.

\section{Monthly typhoid disease trends at the national level}

The typhoid disease cases were aggregated at the national level to determine the monthly proportions from 2012 to 2017. The monthly trends are shown in Figure 4, from which it is evident that the disease incidence peaked at every June-to-July junction and registered a low in the August-September period every year. Figure 4 again confirms outbreaks of the disease during 2015 in the central region and in 2017 in the eastern region. It is also evident that no reduction of the infection took place at the national level.

\section{Trends of typhoid disease incidence in relation to rainfall}

As research generally associates environmental conditions with typhoid disease (Walters et al., 2014; Gu et al., 2017; Mirembe et al., 2019), we explored its association with the average rainfall during the study period. It was observed that the number of typhoid cases always started to raise during the rainy season of March to May, when some places with poor drainage and risk of flooding created conducive environments for bacterial survival and growth. Between May and June, the use of contaminated water commonly continues and resulting into elevated disease rates. Two outbreaks occurred in the central and eastern regions, one in 2015 and one in 2017. The former occurred between February and April (Figure 4D) and the latter between April and June (Figure 4F).

The season-based correlation was carried out using Pearson's correlation coefficient (r), and the results are presented in Table 1, from which it can be seen that the typhoid disease incidence usually has a medium-size positive correlation in the central region during the rainy seasons $(\mathrm{r}=+0.37)$, with a smaller one occurring during the dry seasons $(r=+0.15)$. The eastern region showed minor positive correlations, both for the rainy $(r=0.12)$ and the dry seasons $(r=0.30)$. In the two other regions, the typhoid disease generally had a very small association with rainfall. The variations of the two variables are graphically presented in Figure 6, which confirms the medium-size positive association of the disease with average rainfall, both in the central and in the eastern region for the study period.

\section{Spatio-temporal distribution patterns of typhoid disease}

In this section, we describe and present the spatio-temporal distribution patterns of typhoid disease using disease incidence maps and cluster maps, which enable a clear visualization of disease characteristics in the two-dimensions of space and time.

\section{Disease incidence maps}

Figure 7 presents the typhoid disease incidence maps for the study period, one for each year. As can be seen in Figure 7A, the

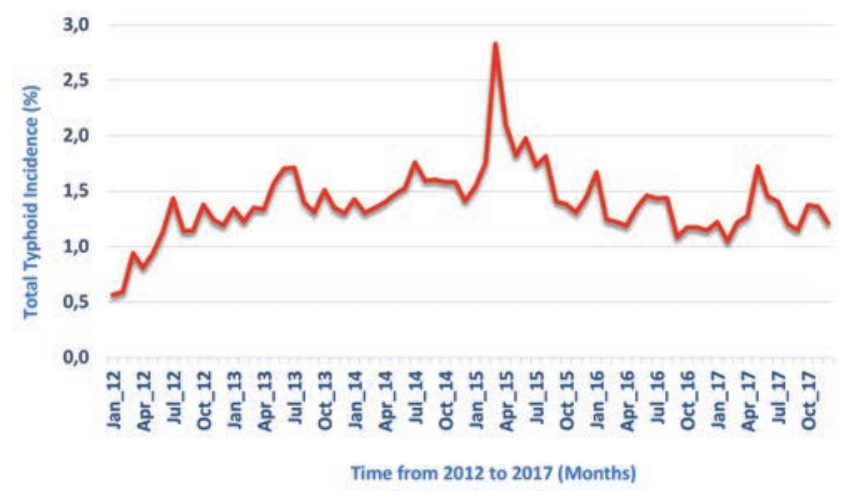

Figure 3. Typhoid disease trends at the national level from 2012 to 2017 .

Table 1. Pearson's Correlation coefficient of typhoid disease incidences with average rainfall for each region and season from 2012 to 2017 .

\begin{tabular}{lcc} 
Region & $\begin{array}{c}\text { Pearson's Correlation Coefficient }(r) \\
\text { Rainy season }\end{array}$ & $\begin{array}{c}\text { Dry season } \\
\text { Central }\end{array}$ \\
Eastern & 0.37 & 0.15 \\
Northern & 0.12 & 0.30 \\
Western & -0.05 & 0.23 \\
\hline
\end{tabular}




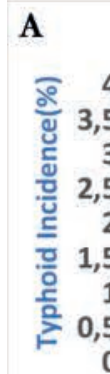

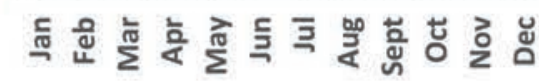

Time(Months)

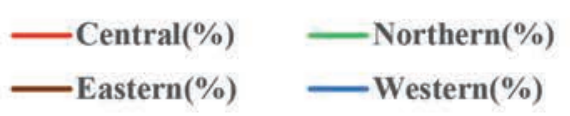

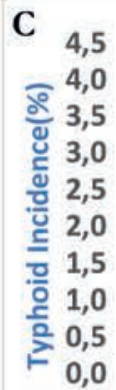

Time(Months)

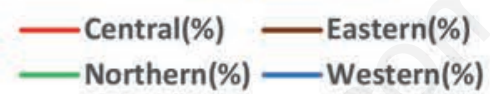

E

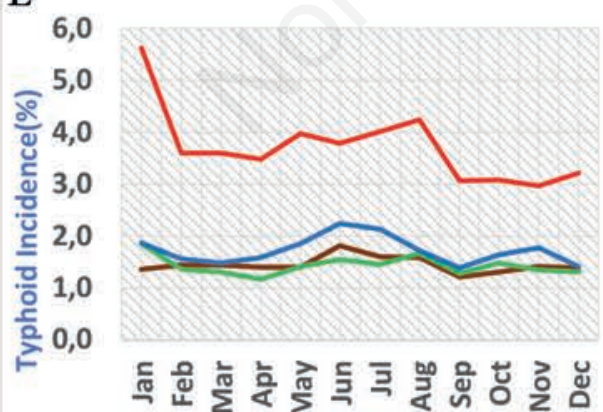

Time(Months)
B 4,5

ஓ 4,0

3,5
$\stackrel{0}{\pi}, 0$

2,5

2,0

들 1,5

1,0

0,5

0,0

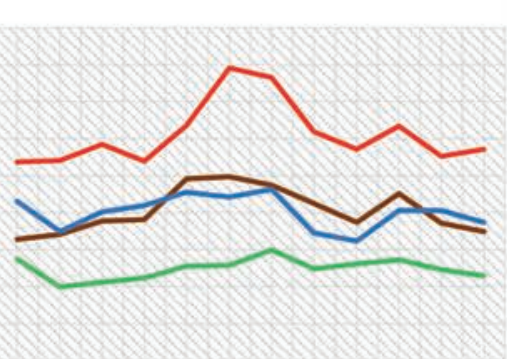

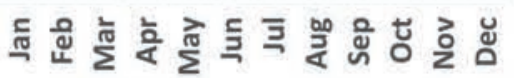

Time(Months)

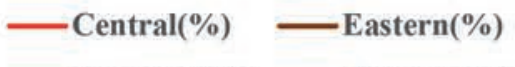

- Northern(\%) - Western(\%)

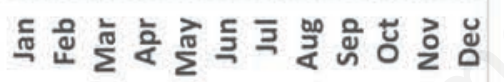

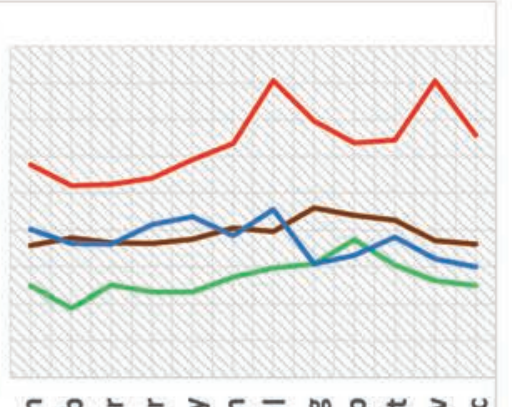

D 10,0

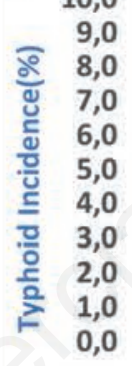

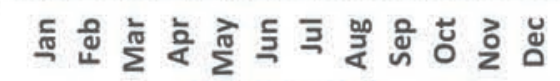
Time(Months)

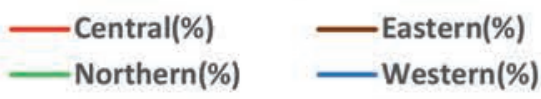

F

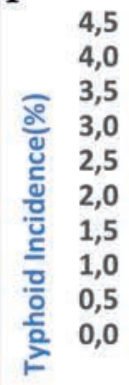

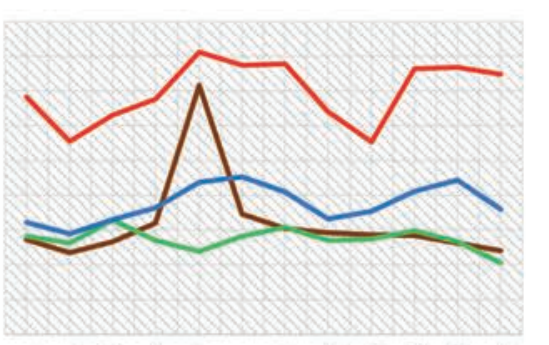

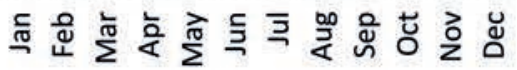

Time(Months)

- Central(\%) - Eastern(\%)

- Northern(\%) Western(\%)

Figure 4. Monthly trends of typhoid disease at the regional level for the period 2012- 2017. A) Monthly trends for the year 2012; B) Monthly trends for the year 2013; C) Monthly trends for the year 2014; D) Monthly trends for the year 2015; E) Monthly trends for the year 2016; F) Monthly trends for the year 2017. 
disease was mainly concentrated in the central region districts during 2012. However, in the following year, high incidence numbers were observed in a few districts in the eastern region. This was repeated during the remainder of the study period, with high incidences in districts distributed in almost all regions. This confirms again that the central region consistently registered the highest typhoid incidences over the entire study period, while the northern region registered the lowest.

\section{Spatio-temporal clustering}

Using the SatScan software package, spatial and temporal typhoid disease clusters were observed. Figure 8 shows the spatial clusters for each of the study years. Figure 8A envisages four clusters in 2012, two of which in the central region, with one cluster each in the eastern and western regions. The disease was even more highly clustered during 2013 (Figure 8B). At this time, one of the two central clusters and the eastern one from 2012 remained the same, while the western region had two additional clusters $(\mathrm{P}<0.01)$, while one of the central clusters had grown and moved further south. During the following four years, the central region maintained its two clusters (Figure 8C-F) in more or less the same districts. Although two other smaller clusters were observed in the eastern region during 2016 and 2017( $\mathrm{P}<0.01$ ), there were fewer clusters in the period 2014-2017 overall. The results are summarized in Table 2 .

Table 2. Spatio-temporal clusters of typhoid disease from 2012 to 2017.

\begin{tabular}{|c|c|c|c|c|c|c|}
\hline Year & $\begin{array}{l}\text { Clusters } \\
\text { detected }\end{array}$ & Districts Involved & Region & $\begin{array}{l}\text { Relative } \\
\text { risk }\end{array}$ & $\begin{array}{l}\text { Population } \\
\text { at risk }\end{array}$ & P-value \\
\hline \multirow[t]{4}{*}{2012} & \multirow[t]{4}{*}{4} & (i) Bukwo, Kween and Kapchorwa & Eastern & 6.53 & 253448 & $<0.01$ \\
\hline & & (ii) Nakaseke, Kiboga, Nakasongola, Luwero, Kyankwanzi and Mityana & Central & 2.25 & 1279562 & $<0.01$ \\
\hline & & (iii) Sheema, Bushenyi, Mbarara, Buhweju and Mitooma & Western & 1.35 & 1295793 & $<0.01$ \\
\hline & & (iv) Mpigi, Butambala and Wakiso & Central & 1.31 & 1608433 & $<0.01$ \\
\hline \multirow[t]{2}{*}{2013} & \multirow[t]{2}{*}{6} & $\begin{array}{l}\text { (i) Bukwo, Kween and Kapchorwa } \\
\text { (ii) Isingiro and Mbarara } \\
\text { (iii) Kiboga, Nakaseke and Mityana } \\
\text { (iv) Bushenyi, Mitooma and Sheema } \\
\text { (v) Kalangala, Masaka, Rakai, Lwengo, Bukomansimbi, Kalungu, } \\
\text { Mpigi, Gomba, Butambala, Lyantonde and Sembabule }\end{array}$ & $\begin{array}{l}\text { Eastern } \\
\text { Western } \\
\text { Central } \\
\text { Western } \\
\text { Central }\end{array}$ & $\begin{array}{l}6.88 \\
2.74 \\
2.75 \\
1.53 \\
1.84\end{array}$ & $\begin{array}{l}303300 \\
886900 \\
686100 \\
681400 \\
15197500\end{array}$ & $\begin{array}{l}<0.01 \\
<0.01 \\
<0.01 \\
<0.01 \\
<0.01\end{array}$ \\
\hline & & (vi) Kyenjojo and Kabarole & Western & 1.15 & 819400 & $<0.01$ \\
\hline 2014 & 3 & $\begin{array}{l}\text { (i) Sembabule and Lyantonde } \\
\text { (ii) Nakaseke, Kiboga, Nakasongola and Luwero } \\
\text { (iii) Masaka and Kalungu }\end{array}$ & $\begin{array}{l}\text { Central } \\
\text { Central } \\
\text { Central }\end{array}$ & $\begin{array}{l}3.20 \\
1.89 \\
1.25\end{array}$ & $\begin{array}{l}346350 \\
984344 \\
480236\end{array}$ & $\begin{array}{l}<0.01 \\
<0.01 \\
<0.01\end{array}$ \\
\hline 2015 & 2 & $\begin{array}{l}\text { (i) Nakaseke, Kiboga, Nakasongola and Luwero } \\
\text { (ii) Masaka and Kalungu }\end{array}$ & $\begin{array}{l}\text { Central } \\
\text { Central }\end{array}$ & $\begin{array}{l}1.91 \\
1.27\end{array}$ & $\begin{array}{l}1010895 \\
488869\end{array}$ & $\begin{array}{l}<0.01 \\
<0.01\end{array}$ \\
\hline \multirow[t]{3}{*}{2016} & \multirow[t]{3}{*}{3} & (i) Nakaseke, Kyankwanzi, Kiboga and Kibaale & Central & 2.31 & 754100 & $<0.01$ \\
\hline & & (ii) Gomba, Kalungu, Bukomansimbi, Mubende, Butambala and Sembabule & Central & 1.50 & 1608400 & $<0.01$ \\
\hline & & (iii) Bukwo, Kween and Kapchorwa & Eastern & 2.07 & 306900 & $<0.01$ \\
\hline 2017 & 3 & $\begin{array}{l}\text { (i)Buikwe and Jinja } \\
\text { (ii) Nakaseke, Kyankwanzi, Kiboga and Kibaale } \\
\text { (iii) Masaka, Kalungu, Bukomansimbi, Rakai, Lwengo, Kalangala, } \\
\text { Mpigi, Butambala and Sembabule }\end{array}$ & $\begin{array}{l}\text { Eastern } \\
\text { Central } \\
\text { Central }\end{array}$ & $\begin{array}{l}1.65 \\
1.86 \\
1.35\end{array}$ & $\begin{array}{l}939300 \\
1553100 \\
1960600\end{array}$ & $\begin{array}{l}<0.01 \\
<0.01 \\
<0.01\end{array}$ \\
\hline
\end{tabular}

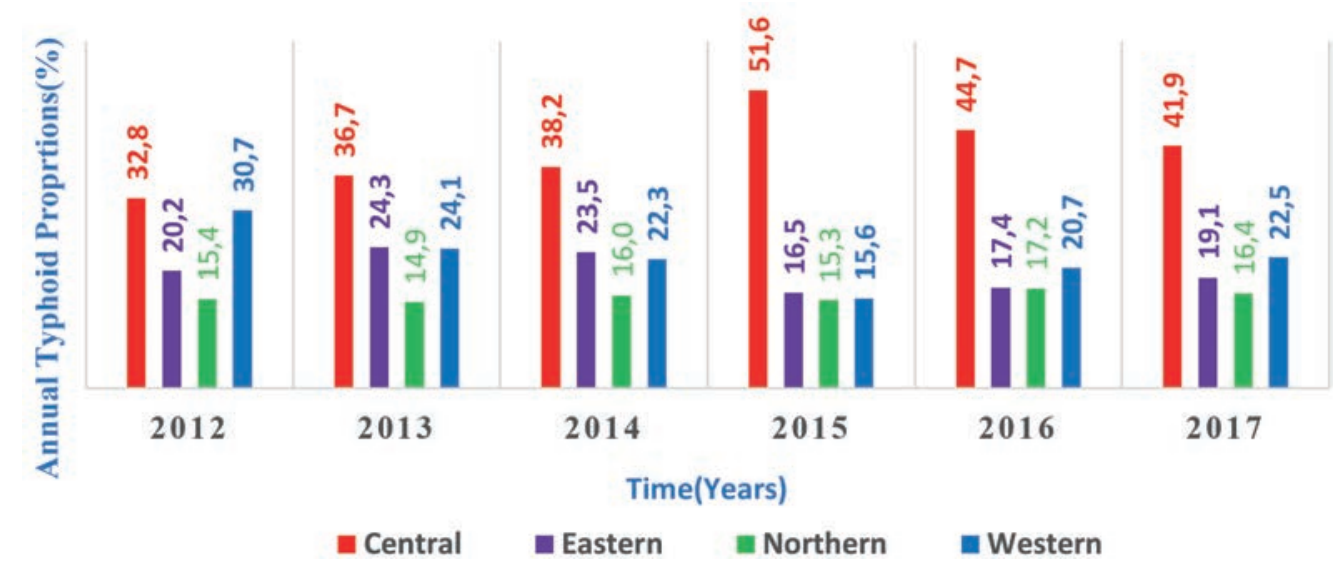

Figure 5. Typhoid disease incidence for the period 2012-2017: annual proportions. 
Overall, most disease clustering was seen in the central region $(\mathrm{P}<0.01)$. The clusters in the eastern region involved the districts Bukwo, Kween and Kapchorwa and had the highest RRs: 6.53 in 2012, 6.88 in 2013 and 2.07 in 2016, which means that more than 300,000 people were at risk $(\mathrm{P}<0.01)$ these years. Though the central region showed a lower RR than the eastern region, it had much higher population at risk.

\section{Discussion}

Spatio-temporal statistics can expose disease incidence trends, disease distribution patterns, high-risk areas and the population at risk, both at the regional and the national level. We were able to reveal spatio-temporal trends and distribution patterns of typhoid disease from 2012 to 2017 in Uganda, including its association with rainfall in different regions and seasons. The study results also showed that the incidence of this disease varies considerably from month to month and from season to season. During the dry season from June to September, there is water scarcity in many places forcing people to share the few available sources, some of which may be contaminated. If so, it will eventually lead to spread of typhoid infections that commonly peak between July and August. However, people also consume water of variable quality from shared sources during dry season that leads to an increased risk of disease transmission as reported by Kabwama et al. (2015) as water sources become contaminated as a result of poor disposal and poor drainage, which creates environments conducive for bac-
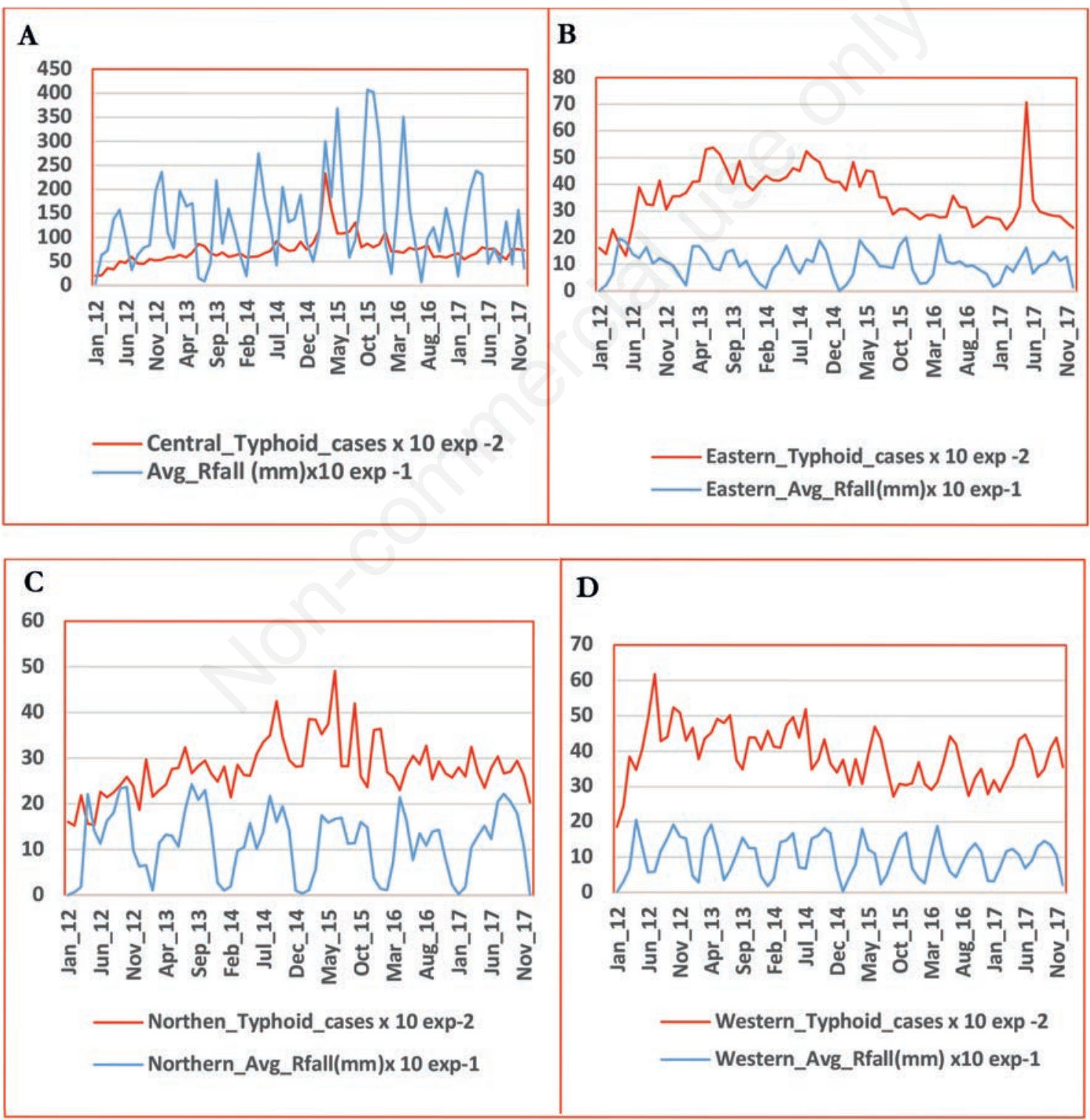

Figure 6. Typhoid disease trends at the regional level and average rainfall for the period 2012-2017. A) Trends in the Central Region; B) Trends in the Eastern Region; C) Trends in the Northern Region; D) Trends in the Western Region. 

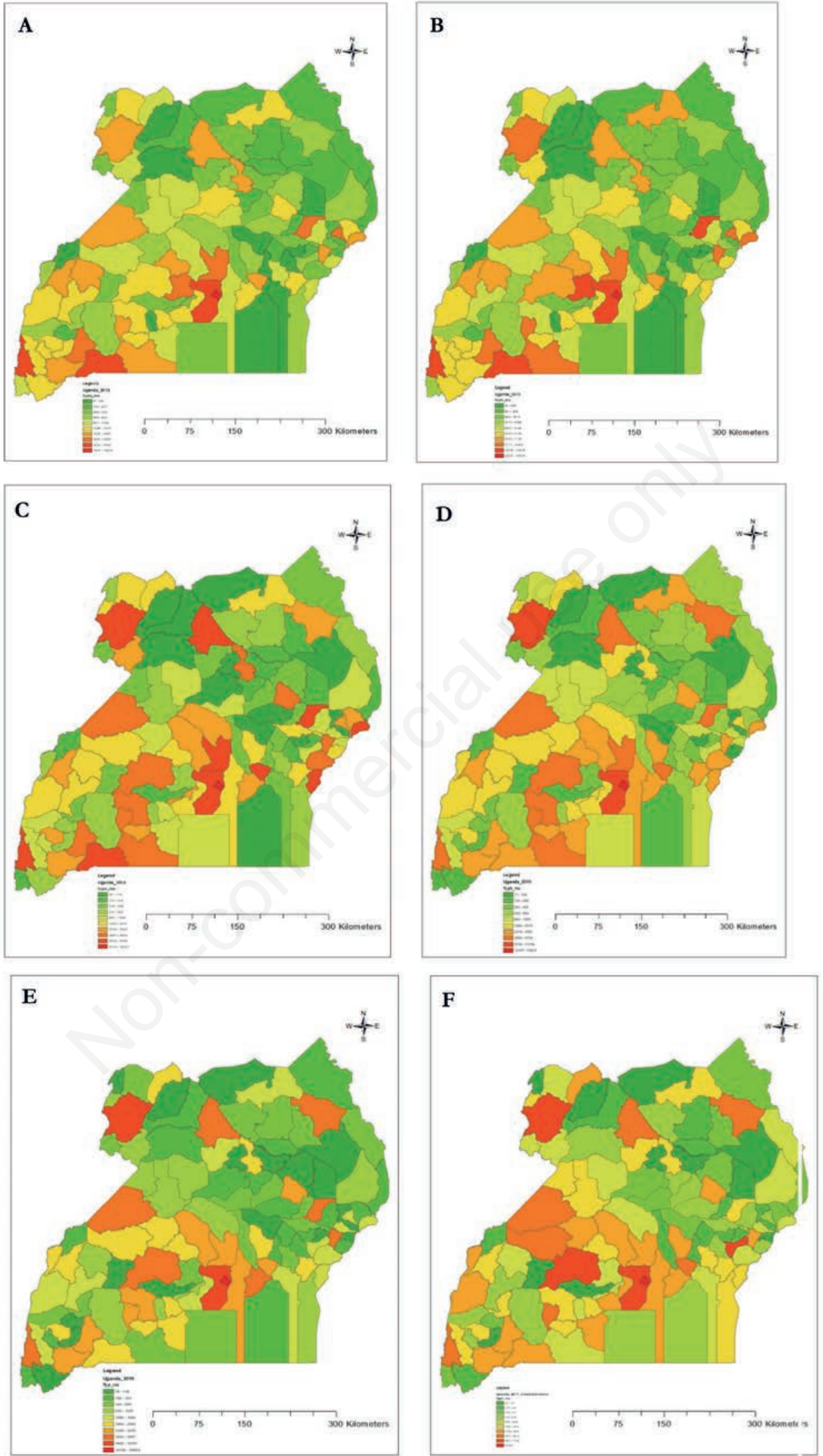

Figure 7. Maps of the annual incidence of typhoid disease for the period 2012-2017. A) 2012; B) 2013; C) 2014; D) 2015 ; E) 2016 ; F) 2017. 

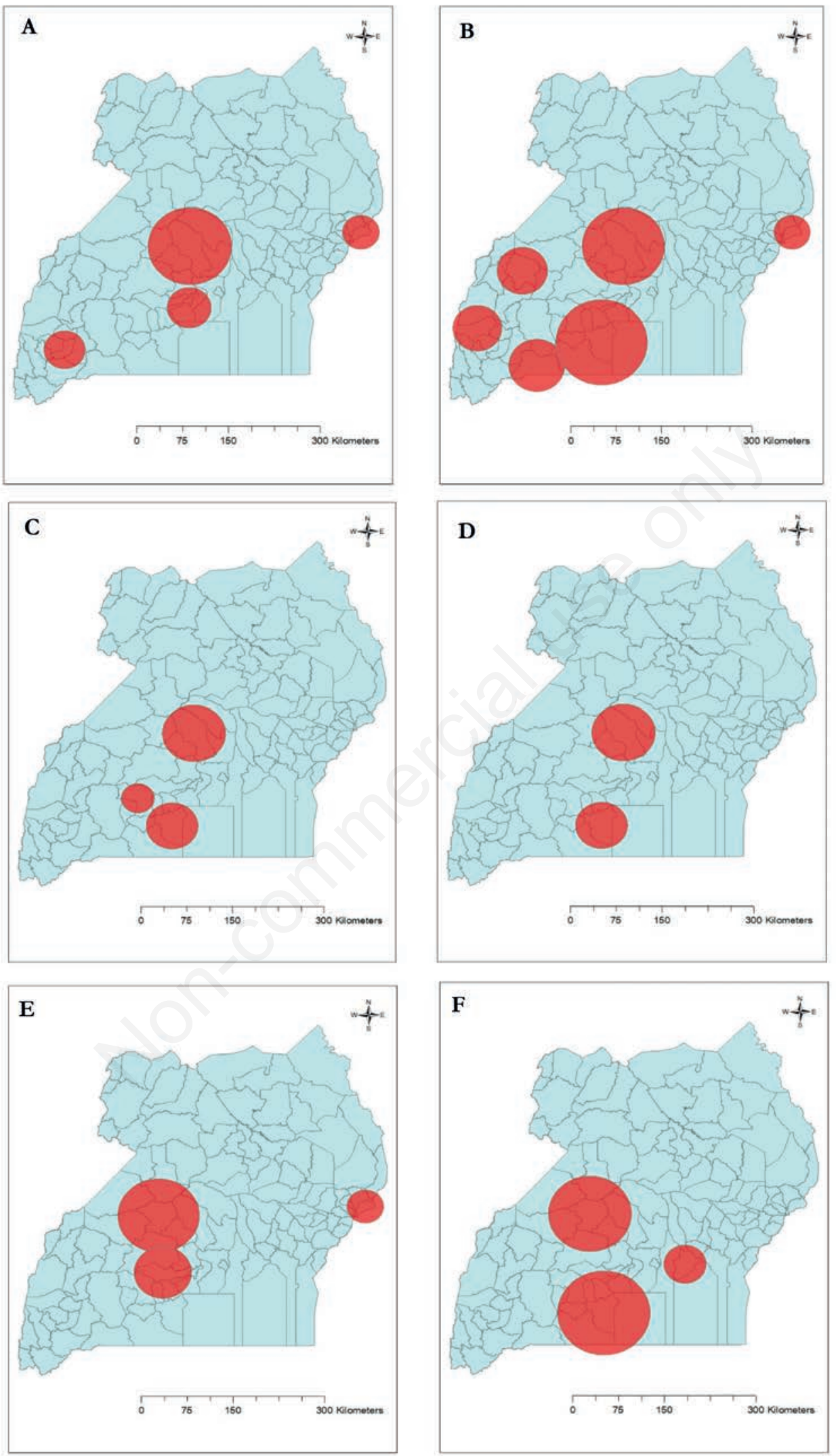

Figure 8. Spatio-temporal clustering of typhoid disease for the period 2012-2017. A) Spatial clustering 2012; B) Spatial clustering 2013; C) Spatial clustering 2014; D) Spatial clustering 2015; E) Spatial clustering 2017; F) Spatial clustering 2017. 
terial growth. The two outbreaks in 2015 and 2017 referred to above both coincided with the rainy season. The source of the 2015 outbreak was confirmed and reported by WHO to be the consumption of contaminated water (WHO, 2015). The 2017 outbreak was similar but this time exacerbated by mudslides displacing people into temporary camps. The poor sanitary conditions in the camps are believed to be the major cause of this outbreak (Mir and Ochen, 2016). These occurrences are a direct consequence of the positive correlation between rainfall and typhoid disease as shown by our study, especially in the central and eastern regions. Indeed, the Central and Eastern regions receive the highest rainfall compared to other regions every year (Nsubuga et al., 2014). This implies that rainfall is a major factor influencing typhoid disease occurrence within these regions, while other factors influence the disease more strongly in the northern and western regions. However, the consistent low disease incidence throughout the study period in the much dryer northern region further emphasizes the role of rainfall for the development of typhoid.

The research further revealed that most of the disease clustering occurred in the central region, followed by the western and eastern regions. The high multi-ethnic population densities with different social and cultural behaviours here lead to congestions in markets, schools, streets and hospitals. In the process of competing for the few available resources, water in particular, it does not help that people's sanitation and hygiene is generally poor. In addition, the monitoring of the street water quality is not strongly enforced by the $\mathrm{MOH}$ and vendors sometimes sell unsafe water (Kabwama et al., 2015), which we believe is a key driver of typhoid transmission thus y contributing to the consistent disease clustering in this region.

One of the clusters in western region covers the districts Isingiro and Mbarara. The area is characterized by the presence of two big, long-term refugee camps, Nakivale and Oruchinga (UNHCR, 2020). The United Nations High Commissioner for Refugees (UNHCR) reports that these camps are in an area of raised water table with poor and loose soils, which do not support proper latrine construction (UNHCR, 2014). Inside these camps, there is also congestion of people with poor waste disposal, sanitation and hygiene (Wamono, 2015). In these camps, as of 2019, the $\mathrm{MOH}$ has reported outbreaks of cholera, an infection with similar drivers as typhoid, which confirms the prevailing poor hygiene. In addition, prolonged droughts in the area and neighbouring areas usually result into water scarcity. Sharing the few available water sources creates a strong chance of contamination. It is thus hardly surprising that this kind of situation contributes to disease transmission explaining the disease clusters we observed there, and we believe that a combination of the causes mentioned are driving the disease clustering.

Our results also revealed a consistent cluster in the eastern region composed of the districts Bukwo, Kween and Kapchorwa. As pointed out by Mir and Ochen (2016) in an OXFAM report, these are some of the districts surrounding Mount Elgon that receive high amounts of rainfall every year, which affects the temporary camps established there. This results in heavy flooding and mudslides, which have caused population displacements and permanent relocations, a fact confirmed by the United Nations Environment Programme (UNEP) and UNMA and is obvious when consulting the rainfall charts shown in Figure 2. In our opinion, the poor living conditions in this part of the country are responsible for the consistent clusters found in the area.

The low rainfall (UNMA, 2016) and low urbanization level in the northern region are likely to be major factors in keeping this part of the country free of typhoid clusters and making it stand as the safest area throughout the study period. As our results show that typhoid disease is rainfall-dependent, this is not surprising.

\section{Limitations of the study}

The following were limitations of the study: i) Some health centres and clinics may not have submitted their clinical data to the national $\mathrm{MOH}$ databases. Missing out such data in the study could have affected the results; ii) some people resort to self-medication without reporting to any health facility, and such cases could have been missed; iii) due to limited data, the study looked only at rainfall as a risk factor of the disease. Other environmental and socialeconomic risk factors were not investigated this time.

\section{Conclusions}

The use of GIS is recommended to reveal hidden spatial patterns difficult to discover by other methods. The disease clustering in the central region is caused by poor drainage, unplanned urbanization and poor monitoring of the quality of water and food items being sold on the streets. In the eastern region clustering was found to be due to strong rainfall causing flooding and mudslides; in the western region it was caused by poor living conditions in refugee camps in addition to strong rainfalls followed by prolonged droughts. The northern region was the safest part of the country throughout the study period.

Knowledge of the kind presented here is essential for efficient planning of resource optimization with respect to disease surveillance. All water sources must be protected from contamination. Exploration of additional risk factors of typhoid disease at the local level should be carried out in the future.

\section{References}

Adams F, 2017. On Airs, Waters, and Places by Hippocrates. Available from: http://classics.mit.edu/Hippocrates/ airwatpl. html. Accessed: January 2020)

Agboola S, Mataimaki BJ, 2017. Spatial Statistical Analysis in the Classification of Some Seasonal Diseases. Journal of Family Med Healthare 3:36-44. doi:10.11648/j.jfmhc.20170302.12

Agwu E, 2012. Distribution of Community Acquired Typhoid Fever among Febrile Patients Attending Clinics in Bushenyi, Uganda: Case Study of the Year 2005. J Med Microbiol Diagn 1:101. doi:10.4172/2161-0703.1000101

Ahangarcani M, Farnaghi M, Shirzadi MR, Pilesjö P, Mansourian A, 2019. Predictive risk mapping of human leptospirosis using support vector machine classification and multilayer perceptron neural network. Geospat Health 14:711.

Baaghideh M, Hamidian A, Roudbari AD, Mayvaneh, F, 2016. Modeling and Spatial Epidemiology of Diarrhea in Mazandaran Province. Iran J Epidemiol 12:41-50.

Bergquist R, Rinaldi L, 2010. Health research based on geospatial tools: a timely approach in a changing environment. J Helminthol 84:1-11. doi:10.1017/S0022149X09990484

Elliott P, Wartenberg D, 2004. Spatial epidemiology: current approaches and future challenges. Environ Health Perspect 112:998-1006. doi:10.1289/ehp.6735

Gu H, Fan W, Liu K, Qin S, Li X, et al., 2017. Spatio-temporal 
variations of typhoid and paratyphoid fevers in Zhejiang Province, China from 2005 to 2015. Sci Rep 7:5780. doi:10.1038/s41598-017-05928-3

Jong-Hoon K, 2017. African Risk Prediction Model: Mapping the burden of Typhoid Fever in Africa. 10 ${ }^{\text {th }}$ International Conference on typhoid fever and other invasive salmonelloses, Kampala Uganda. Available from: 23-African-Risk-FactorPrediction-Model-and-Implications-for-Vaccination-Strategies. pdf

Kabwama SN, Bulage L, Nsubuga F, Pande G, Oguttu DW, et al., 2015. A large and persistent outbreak of typhoid fever caused by consuming contaminated water and street-vended beverages: Kampala, Uganda, January - June 2015. BMC Public Health 17:23.

Kasoro F, Yoti Z, Bakyaita N, Gaturuku P, Katz R, et al., 2013. IDSR as a Platform for Implementing IHR in African Countries. Biosecur Bioterror 11:163-9. doi:10.1089/ bsp.2013.0032

Lee JS, Mogasale V, Mogasale V V, Lee K, 2016. Geographical distribution of typhoid risk factors in low and middle-income countries. BMC Infect Dis 16:732. doi:10.1186/s12879-0162074-1

Malone JB, Bergquist R, Martins M, Luvall JC, 2019. Use of Geospatial Surveillance and Response Systems for VectorBorne Diseases in the Elimination Phase. Trop Med Infect Dis 4:15. doi:10.3390/tropicalmed4010015

Marks F, et al., 2017. Incidence of invasive salmonella disease in sub-Saharan Africa: a multicentre population-based surveillance study. Lancet Glob Health 5:e310-23.

Mirembe BB, Mazeri S, Callaby R, Nyakarahuka L, Kankya C, Muwonge A, 2019. Temporal, spatial and household dynamics of Typhoid fever in Kasese district, Uganda. PLoS One 14:e0214650. doi:10.1371/journal.pone.0214650

Mir X, Ochen EA, 2016. Fresh Analysis of the Humanitarian Capacity in Uganda, OXFAM. Available from: https://cngcdn.oxfam.org/uganda.oxfam.org/s3 fs-public/file_attachments/ELNHA\%20REPORT.pdf

Muhindo R, Joloba EN, Nakanjako D, 2016. Health Management Information System (HMIS); Whose Data is it Anyway? Contextual Challenges. Review Pub Admin Manag 4:190. doi: $10.4172 / 2315-7844.1000190$

National Environmental Management Authority (NEMA), 2009. Uganda: Atlas of our Changing Environment. Available from: https:/na.unep.net/atlas/uganda/downloads/uganda-atlas2009.pdf

Nsubuga FWN, Botai OJ, Olwoch JM, Rautenbach CJD, Bevis Y, Adetunji AO, 2014. The nature of rainfall in the main drainage sub-basins of Uganda. Hydrol Sci J 59:278-99.

Prates MO, Kulldorff M, Assunção RM, 2014. Relative risk estimates from spatial and space-time scan statistics: are they biased?. Stat Med 33:2634-44. doi:10.1002/sim.6143

Rajabi M, 2015. Disease susceptibility mapping using spatial modeling techniques, GIS Center, Department of Physical Geography and Ecosystem Science, Lund University. Available from: https://www.nateko.lu.se/sites/nateko.lu.se/ files/mohammadreza-rajabi-first_year_seminar-17-08-2015v4.pdf

Satscan, 2019. SaTScan software for the spatial, temporal and space-time scan statistics. Available from: https://www.satscan.org/download_satscan.html Accessed: August 2020)
Smith GD, 2002. Commentary: Behind the Broad Street pump: aetiology, epidemiology and prevention of cholera in mid-19th century Britain. Int J Epidemiol 31:920-32.

Thieme EG, Jacobs C, 2012. Risk Mapping Uganda: Sector Disaster Risk Production and Emergency Aid 2012. Available from: https://www.cordaid.org/en/wp-content/uploads/sites/3/ 2013/08/Uganda_risk_mapping_20120130_ETG.pdf

Tiwari R, Nayak S, 2017. Drinking water, Sanitation and Water borne diseases. Econ Weekly J 52. Available from: https://www.epw.in/journal/2017/23/commentary/drinkingwater-sanitation-and-waterborne-diseases.html

UBOS, 2012. Statistical Abstract 2012, Uganda Bureau of Statistics. Available from: http://www.ubos.org/ onlinefiles/ uploads/ubos/pdf\%20documents/2012StatisticalAbstract.pdf

UBOS, 2016. The National Population and Housing Census 2014. Main Report, Kampala, Uganda. Available from: https://www. ubos.org/wp-content/uploads/publications/ 03_20182014_ National_Census_Main_Report.pdf_

UNHCR, 2014. Oruchinga Fact Sheet 2014, UNHCR Uganda. Available from: https://data2.unhcr.org/fr/documents/download $/ 48491$

UNHCR, 2020. Nakivale Settlement Profile. Isingiro District, Uganda. July 2020. Available from: https:/unhabitat.org/ sites/default/files/2020/08/200720_nakivale_settlement_profile_web.pdf

UNMA, 2019. The Seasonal Rainfall outlook for June to August 2019 over Uganda. Available from: http://envalert.org/wp-content/uploads/2019/06/June-to-August_2019-SeasonalRainfall-Outlook.pdf

UNMA, 2016. September to December 2016 seasonal rainfall outlook over Uganda. Available from: https:/www.newvision.co. ug/new_vision/news/1435709/uganda-national-meteorological-authority

Walters MS, Routh J, Mikoleit M, Kadivane S, Ouma C, Mubiru D, 2014. Shifts in Geographic Distribution and Antimicrobial Resistance during a Prolonged Typhoid Fever Outbreak Bundibugyo and Kasese Districts, Uganda, 2009-2011. PLoS Negl Trop Dis 8:e2726. doi:10.1371/journal.pntd.0002726

Weaver CG, Ravani P, Oliver MJ, Austin PC, Quinn RR, 2015. Analyzing hospitalization data: potential limitations of Poisson regression. Nephrol Dialysis Transplantation 30:1244-49. doi:10.1093/ndt/gfv071

WHO, 2015. Water, sanitation and hygiene for accelerating and sustaining progress on neglected tropical diseases, a global strategy 2015-2020. Available from: https://www.who. int/water_sanitation_health/publications/wash-and-ntd-strategy/en/

WHO, 2017. WHO Health Emergencies Programme in the African Region: Annual Report 2016. Geneva: World Health Organization; 2017. Available from: https://apps.who.int/iris/ handle/10665/258535

Wamono E, 2015. Uganda Situation Report on Refugees from Burundi, UNICEF Co-Situation Report, June 2015. Available from: https://reliefweb.int/report/uganda/uganda-situationreport-refugees-burundi-17-june-2015

World Population Review (WPR), 2020. Uganda Population 2020. Available from: http://worldpopulationreview. com/countries/ uganda-population/ 